\section{Public Health Genomics}

Public Health Genomics 2012;15:11-21

DOI: $\underline{10.1159 / 000327159}$
Received: June 11, 2010

Accepted after revision: March 1, 2011

Published online: June 30, 2011

\title{
The General Public's Understanding and Perception of Direct-to-Consumer Genetic Test Results
}

\author{
J.W. Leighton ${ }^{a, b} \quad$ K. Valverde ${ }^{a} \quad$ B.A. Bernhardt ${ }^{c}$

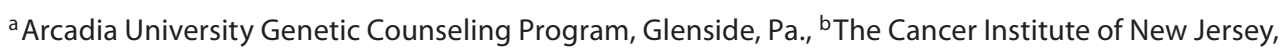 \\ University of Medicine and Dentistry of New Jersey, New Brunswick, N.J., and ${ }^{\complement}$ Center for the Integration \\ of Genetic Healthcare Technologies, University of Pennsylvania, Philadelphia, Pa., USA
}

\section{Key Words}

Direct-to-consumer genetic tests • Direct-to-consumer tests $\cdot$ Direct-to-consumer test results $\cdot$ General public $\cdot$ Genetic counselors • Genetic professionals • Perceptions • Understanding

\begin{abstract}
Background/Aims: Direct-to-consumer (DTC) genetic testing allows consumers to discover their risk for common complex disorders. The extent to which consumers understand typical results provided by DTC genetic testing is currently unknown. Misunderstanding of the results could lead to negative consequences including unnecessary concern, false reassurance or unwarranted changes in screening behaviors. We conducted a study to investigate consumers' perceptions and understanding of DTC test results. Methods: An online survey was posted on Facebook that included questions relating to 4 sample test results for risk of developing colorectal cancer, heart disease and skin cancer. Genetic counselors were used as a comparison group. Results: 145 individuals from the general public and 171 genetic counselors completed the survey. A significant difference was found between the way the general public and genetic counselors interpreted the meaning of the DTC results. The general public respondents also believed that results in all 4 scenarios would be significantly more helpful than the genetic coun-
\end{abstract}

selors did. Although the majority of general public respondents rated the results as easy to understand, they often misinterpreted them. Conclusions: These findings imply that the general public has the potential to misinterpret DTC results without appropriate assistance. Further research is needed to explore optimal methods of providing DTC test results and ways to minimize the risk of negative consequences for consumers.

Copyright $\odot 2011$ S. Karger AG, Basel

\section{Introduction}

As direct-to-consumer (DTC) genetic tests become more available, concerns have been raised about their usefulness in medical care as well as the public's ability to understand and interpret the meaning of personalized test results [1-3]. Many of today's DTC genetic tests use whole genome scans to screen a large number of single nucleotide polymorphisms (SNPs) which have been found to correlate with an increased or decreased risk for specific disorders or traits within the general population. Once the testing is complete, the results are compiled from previously established risk values and are either mailed back to the consumer or are available for viewing in an online format. Social networkers have been identified by the medical community as possibly some of the 
first adopters of DTC testing since many of these tests are currently available and found on the internet [4]. The early adopters' motivation for testing has varied but has included general curiosity about genetic make-up and a desire to obtain information as to whether a particular disease runs in the family [4].

The downside of current DTC genetic testing is that the SNPs used for the testing are generally not causative of disease and may account for a very small change in risk for developing a disease [5, 6]. As an example, a study that linked SNPs in the FGFR2 gene to risk of developing breast cancer found only a 1.2-fold increased risk over the general population for individuals carrying the risk-associated allele [7]. Furthermore, current research is demonstrating that associations found between some SNPs and diseases are not consistent across multiple gene-disease association studies. In an analysis of 166 gene-disease association studies, it was found that only 6 genes were shown to have same disease association in $75 \%$ of the studies [8]. These limitations have led to concerns about the clinical validity and utility of SNP-based risk assessment and have led to calls for more federal oversight and regulation of DTC genetic testing for disease risk [9]. Current federal oversight is lacking with regards to DTC genetic testing because genetic testing has not yet been defined as a specialty area by the Centers for Medicare and Medicaid Services (CMS) under Clinical Laboratory Improvement Amendments. Thus, the only current oversight of genetic laboratories relates to quality control of reagents and equipment. Without further oversight, DTC companies are not required to perform any type of proficiency testing to even ensure that their results are analytically valid $[1,10]$. Meanwhile, state governing bodies are also recognizing the potential risks associated with DTC testing, with 13 states already prohibiting DTC genetic testing [1].

Other concerns about DTC testing relate to possible undue anxiety after receiving a result indicating slightly increased disease risk [3] or possible false reassurances from a result indicating decreased disease risk results [1], both of which could lead to unwarranted actions [2]. Although many of the SNPs identified in whole genome scans only convey a very small increase or decrease in risk for a particular disease, and other disease risk factors such as family history or lifestyle factors may be more useful as a basis for recommendations to reduce risk [5, $11]$, it has been speculated that consumers may make inappropriate healthcare decisions or request unwarranted changes to their screening modalities based on DTC results $[1,2]$. Participants consisting of social networkers from a recent study about DTC testing indicated that they might indeed use the results from DTC tests to make changes to their healthcare management, but would consult their primary care physician before making any changes [4].

Proponents of DTC genetic testing have maintained that the general public has the right to access their genetic information about disease risks, and that DTC testing increases accessibility to genetic testing as it offers testing in a convenient manner to consumers. DTC companies argue that this increased convenience and accessibility will ultimately keep the price of genetic testing lower for consumers [5]. Proponents have also argued that DTC tests will raise consumer awareness about their genetic risks for various conditions and may motivate them to take action to lower their risk [12]. Such action, however, is predicated on the notion that individuals in the general public can accurately and appropriately interpret the results disclosed to them through DTC testing.

The ability of the general public to understand DTC genetic test results rests on their ability to understand and interpret the complex risk values associated with DTC genetic test results. The ability of individuals to understand risk values similar to those reported with DTC results requires an ability to comprehend, use and attach meaning to numbers, which is referred to as numeracy [13]. Unfortunately, numeracy skills of the general public, especially those with less education, are relatively low [14]. One large national study found that only $13 \%$ of individuals in the general population were proficient in numeracy skills and that $66 \%$ had only intermediate or basic numeracy skills [15]. Other numeracy studies have shown that individuals have difficulties comparing different risk value presentations [16] and converting a numerical value to a percentage [17]. In addition, low numeracy skills have been shown to be associated with developing inappropriate risk perceptions [14]. In one study about DTC testing, less than half of the participants felt that they could adequately interpret DTC results on their own, while over one-third of respondents considered the information from DTC tests to be a medical diagnosis [4]. Furthermore, the literacy demands of information supplied on DTC genetic testing websites is high [18]. These studies provide evidence that the general public may not be equipped to interpret results from DTC tests without assistance from an appropriate medical professional. It should be noted that DTC genetic testing companies such as Navigenics, 23andMe and DeCode indirectly acknowledge that some consumers may need professional assistance with understanding results by suggesting a consultation with a genetic counselor. 
It is important to investigate the general public's perceptions and misperceptions about DTC genetic testing, as well as their ability to understand and interpret results, so as to develop recommendations relating to educational and counseling needs. We investigated this by surveying members of the general public, as well as genetic counselors, who were used as a comparison group. We hypothesized that there would be significant differences between the general public and genetic counselors in terms of interpretation of test results, assessment of the helpfulness and clinical utility of test results, and in the concern engendered by test results.

\section{Subjects and Methods}

\section{Participants}

Subjects were members of the social networking site Facebook who chose to take part in the online survey. An initial recruitment message was sent to all 382 of the principal investigator's immediate 'friends' on Facebook inviting them to participate in the study and providing them with a link to the survey on surveymonkey. com. In that initial message, each 'friend' was asked to please forward the invitation onto at least 5 other individuals that were members of Facebook. A single reminder invitation message was sent to the 382 individuals initially contacted after approximately 30 days. In addition, the same invitation to participate in the online study was posted in various active social 'groups' that are openly accessible on Facebook, such as 'Barack Obama (One Million Strong for Barack)', 'Yankees Fans' and 'Surveys'. General public participants were required to be U.S. residents over the age of 18 and to be a current member of the social networking site Facebook.

Comparison subjects were members of the National Society of Genetic Counselors residing in the U.S. who chose to take part in the online survey. The society maintains a listserv that includes approximately 1,500 members, and a notification on that listserv provided members a link to the survey on surveymonkey.com. Genetic counselors were used as a comparison group in this study because they are recognized by DTC genetic testing companies as the providers who should be consulted by consumers seeking assistance with understanding genetic testing results. Because of their training in risk assessment and communication of genetic risk, genetic counselors are acknowledged as the category of healthcare providers who can assist consumers in understanding DTC results [19].

\section{Survey Instrument}

We developed 2 versions of a survey to be administered online: one for the general public and one for genetic counselors. Except for sociodemographic questions, the 2 versions were identical. In both versions, the survey began with a brief description of DTC genetic tests and the information that they provide to consumers. The survey included 4 mock test result scenarios using language directly from 3 prominent DTC companies (this language is in the public domain on the internet and was properly cited within the survey). Each scenario was accompanied by a series of questions to assess understanding of the results and hypothetical intentions based on the results. In this study, the understanding of the DTC test results by members of the general public was assessed by comparing the participants' perceived level of risk with those of the comparison group of genetic counselors. Other questions included belief that results would be helpful in deciding future medical management, the level of concern elicited by the results, the perceived understandability of results, and the likelihood of seeking assistance from various sources after testing. Five-point Likert scales were used to record the answers for each question. The survey was piloted for understandability by a convenience sample of 5 young adults from the general population.

The first scenario in the survey was taken from the Decode website and implied an increased risk for colorectal cancer. Test results were presented in relative risk format, overall risk percentage format and a pictorial format. The second scenario was also taken from the Decode website, but it implied a decreased risk of heart disease. The sample result presentation was the same as the formats used in the first scenario. The third scenario was taken from the 23andMe website and implied a decreased risk for basal cell carcinoma. The test results in this scenario were presented in an odds ratio format as well as a descriptive word format that stated 'slightly lower odds of developing basal cell carcinoma'. The fourth scenario was taken from the Navigenics website, and it implied a decreased risk of colon cancer. The test results in this scenario were presented in an absolute risk format, a descriptive word format that stated 'below average' risk and a pictorial representation of the risk.

\section{Statistical Analysis}

Several tests were used to investigate whether there were differences between the general public sample and the genetic counselor sample in terms of the understanding of the DTC results, the belief about the helpfulness of the DTC results in medical management and the level of concern after reading the DTC results. The responses to each Likert scale question were assessed for differences between the 2 groups using the MannWhitney $U$ test. A p-value of less than 0.05 was considered significant.

Chi square analyses were performed on the general public data to investigate an association between the participants' self-assessment of their ability to interpret the DTC results and accuracy of the interpreted risk from the DTC sample results. A correct risk assessment for each scenario was defined as the modal risk assessment answer from the genetic counselor group for each scenario. Microsoft excel and the statistical software SPSS, version 18.0, were used in the analysis of the data.

\section{Results}

A total of 145 individuals from the general public and 171 genetic counselors responded to the survey. Data from all partially completed surveys were used if all applicable questions required for an analysis were answered. 
Table 1. Demographics of general public $(n=105)$ and genetic counselor $(n=149)$ respondents

\begin{tabular}{|c|c|c|c|c|}
\hline & \multicolumn{2}{|c|}{ General public } & \multicolumn{2}{|c|}{ Genetic counselors } \\
\hline & $\mathrm{n}$ & $\%$ & $\mathrm{n}$ & $\%$ \\
\hline \multicolumn{5}{|l|}{ Age, years } \\
\hline $18-23$ & 42 & 40.4 & 2 & 1.4 \\
\hline $24-29$ & 43 & 41.3 & 63 & 45.3 \\
\hline $30-39$ & 9 & 8.7 & 50 & 36.0 \\
\hline $40+$ & 10 & 9.6 & 24 & 17.3 \\
\hline \multicolumn{5}{|l|}{ Sex } \\
\hline Female & 79 & 75.2 & 144 & 96.7 \\
\hline Male & 26 & 24.8 & 5 & 3.3 \\
\hline \multicolumn{5}{|l|}{ Race } \\
\hline White, Non-Hispanic/Latino & 98 & 93.1 & 140 & 93.3 \\
\hline Other & 7 & 6.9 & 10 & 6.7 \\
\hline \multicolumn{5}{|l|}{ Education level } \\
\hline High school only & 2 & 2.0 & - & - \\
\hline Some college & 17 & 16.2 & - & - \\
\hline Bachelor's degree & 62 & 59.0 & - & - \\
\hline Master's degree & 18 & 17.1 & - & 100 \\
\hline Professional or doctoral degree & 6 & 5.7 & - & - \\
\hline \multicolumn{5}{|c|}{ Employment or education in healthcare or biological sciences } \\
\hline Yes & 59 & 56.1 & 149 & 100 \\
\hline No & 46 & 43.9 & 0 & 0 \\
\hline
\end{tabular}

Table 2. General public's familiarity with DTC testing

\begin{tabular}{llr}
\hline Familiarity & $\mathrm{n}$ & $\%$ \\
\hline A great deal & 10 & 9.5 \\
A fair amount & 20 & 19.0 \\
A little bit & 26 & 24.8 \\
Not at all & 49 & 46.7 \\
\hline
\end{tabular}

\section{Demographics}

Respondents from the general public were relatively young, with mean age of 28.1 years and a range of 19-83 years old (table 1). Respondents were also well educated with more than $81 \%$ holding a bachelor's degree or higher and largely Caucasian with $93.1 \%$ self-identifying as white, non-Hispanic/Latino. Additionally, over $50 \%$ of the participants either obtained a degree or are currently working in a field related to healthcare and/or biological sciences. Participants generally had little familiarity with DTC genetic testing (table 2).

Genetic counselor respondents were also relatively young, with a mean age of 32.5 years and a range of 23-56 years old. Respondents were also largely Caucasian, with $93.3 \%$ of the respondents self-identifying as white, non-
Hispanic/Latino (table 1). Over $95 \%$ of respondents had heard of DTC genetic testing before participating in this survey, and about a quarter of the respondents had previously been asked about DTC genetic testing results during a genetic counseling session.

\section{Scenario 1}

For scenario 1, nearly all (89\%) genetic counselors thought that a 1.45 relative risk of colon cancer implied a slightly greater risk for developing disease, while only 74 respondents (58.2\%) in the general public interpreted the results in the same way (fig. 1). This difference between the 2 groups was significant using the Mann-Whitney $U$ test $(\mathrm{p}=0.004)$. The majority of genetic counselors $(79.6 \%)$ felt that results given in scenario 1 were either neutral or unhelpful with regards to managing medical care, while the majority of the general public (58.3\%) felt that the results were helpful $(\mathrm{p}=0.000$; Mann-Whitney $\mathrm{U}$ test). The vast majority of the general public and the genetic counselors reported that their concerns about their risk for colon cancer would be either unchanged or only minimally increased by the DTC results presented in scenario 1 , and the difference between the 2 groups was not significant ( $\mathrm{p}=0.146$; Mann-Whitney U test). 
Fig. 1. General public's and genetic counselors' assessment of risk, helpfulness and concern relating to scenario 1 - increased risk of colon cancer.

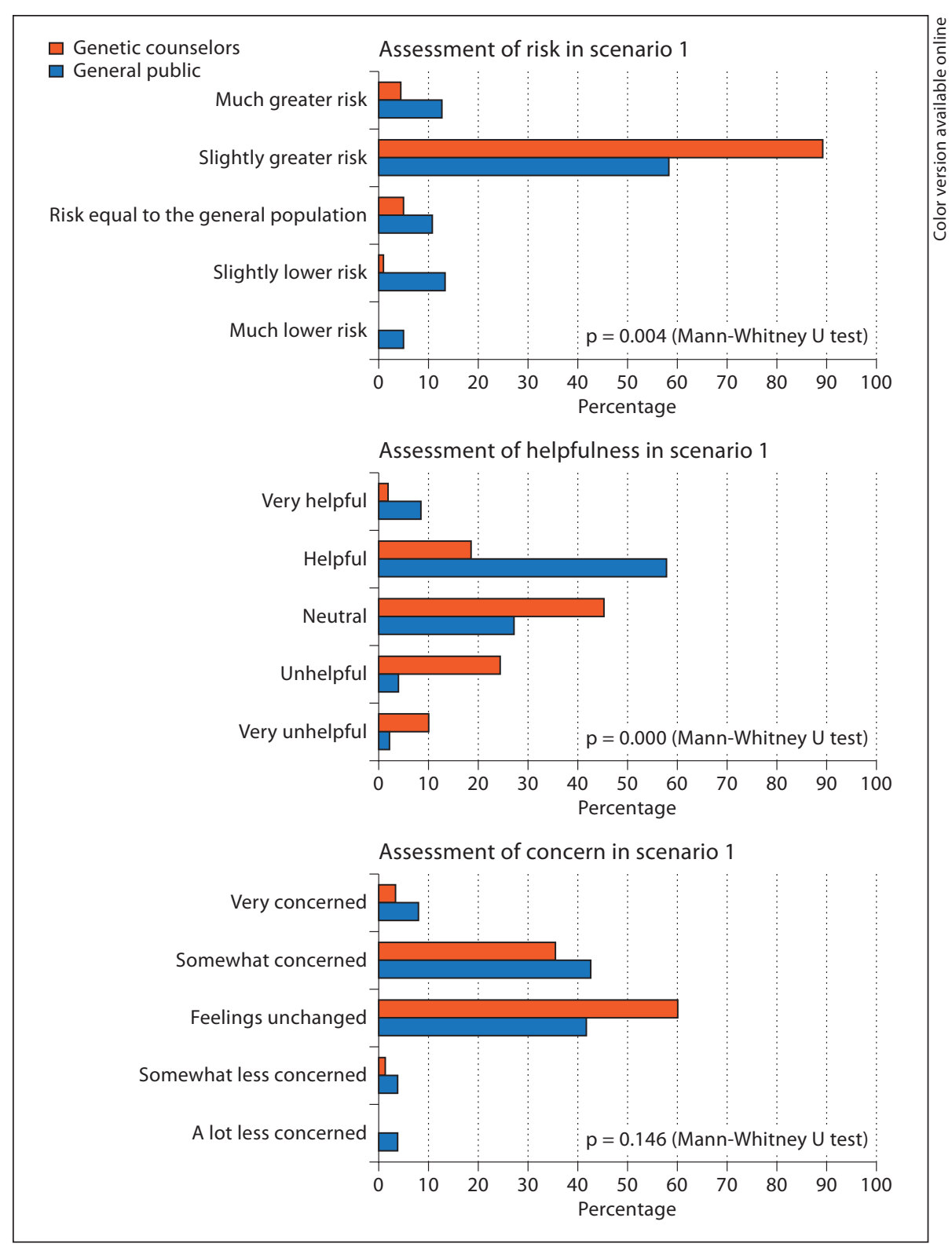

\section{Scenario 2}

For scenario 2, the vast majority (77.3\%) of the genetic counselors thought that a 0.83 relative genetic risk of heart disease implied a slightly lower risk for developing the condition, while only 74 respondents $(58.0 \%)$ in the general public interpreted the results in the same way (fig. 2) ( $\mathrm{p}=0.016$; Mann-Whitney U test). The majority of genetic counselors $(92.9 \%)$ felt that results given in scenario 2 were either neutral or unhelpful with regards to managing medical care, while the majority of the general public (52.8\%) felt that the results were helpful ( $p=0.000$;
Mann-Whitney U test). Thirty-four percent of the general public (34.5\%) reported that they might experience increased concern from the DTC results presented in scenario 2, while only a small proportion of the genetic counselors felt the same way (5.8\%) $(\mathrm{p}=0.001$; MannWhitney U test).

\section{Scenario 3}

For scenario 3, the majority of genetic counselors (73.9\%) and respondents in the general public (72.4\%) thought that a genotype that decreased their odds about 
Fig. 2. General public's and genetic counselors' assessment of risk, helpfulness and concern relating to scenario 2 - decreased risk of heart disease.

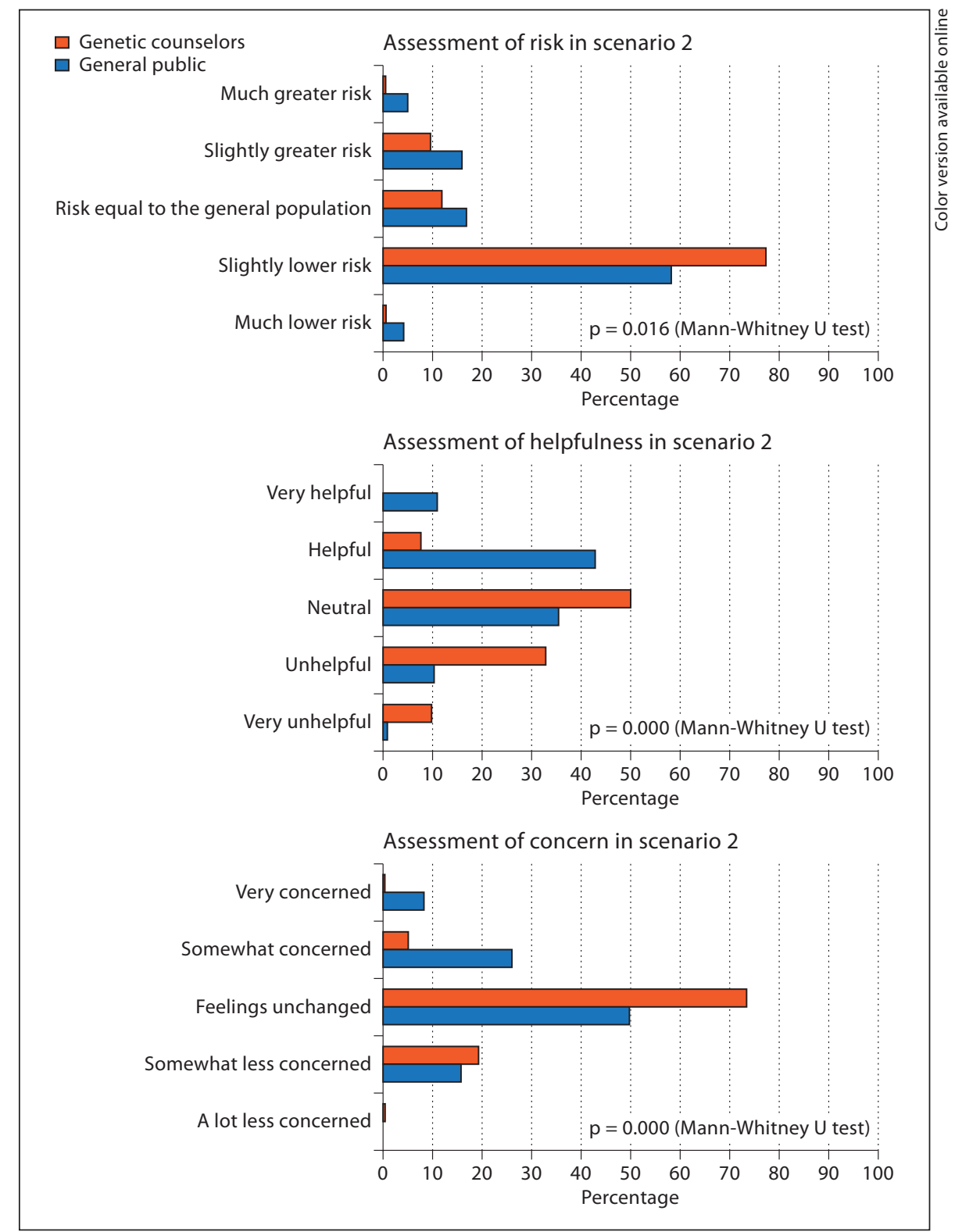

1.3-fold implied a slightly lower risk for developing basal cell carcinoma (fig. 3). This difference between the 2 groups was not significant using the Mann-Whitney U test $(\mathrm{p}=0.741)$. Nearly all of the genetic counselors (94.1\%) felt that results given in scenario 3 were either neutral or unhelpful with regards to managing medical care, while a significant portion of the general public (42.1\%) felt that the results were helpful ( $\mathrm{p}=0.000$; MannWhitney $\mathrm{U}$ test). The vast majority of the general public and the genetic counselors reported that their concerns about their risk for basal cell carcinoma would be either unchanged or only minimally decreased by the DTC results presented in scenario 3 , and the difference between the 2 groups was not significant ( $\mathrm{p}=0.452$; Mann-Whitney U test).

\section{Scenario 4}

For scenario 4, the majority of genetic counselors (70.1\%) thought that a $4.1 \%$ life-time risk and relative risk that was 'below average' of developing colon cancer implied a slightly lower risk for developing disease, while 63 respondents (60.6\%) in the general public inter- 
Fig. 3. General public's and genetic counselors' assessment of risk, helpfulness and concern relating to scenario 3 - decreased risk of basal cell carcinoma.

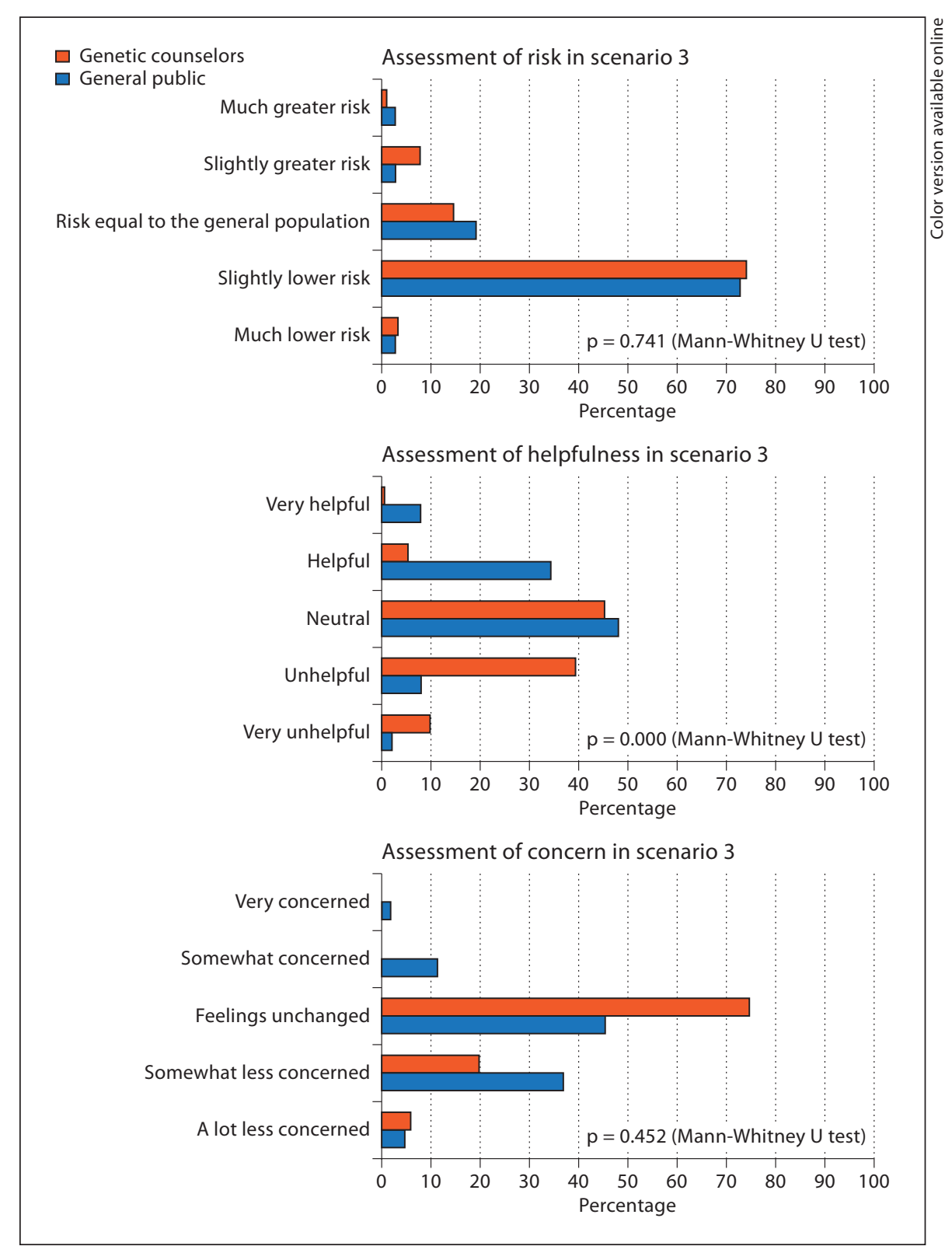

preted the results in the same way (fig. 4). This difference between the 2 groups was significant using the Mann-Whitney $U$ test $(p=0.000)$. Nearly all of genetic counselors (88.4\%) felt that results given in scenario 4 were either neutral or unhelpful with regards to managing medical care, while the majority of the general public $(51.4 \%)$ felt that the results were helpful ( $p=0.000$; Mann-Whitney $U$ test). The vast majority of the general public and the genetic counselors reported that their concerns about their risk for colon cancer would be either unchanged or only minimally decreased by the
DTC results presented in scenario 4 , and the difference between the 2 groups was not significant ( $p=0.057$; Mann-Whitney U test).

\section{Assessment of Understanding of Results}

Chi square analyses were performed on the general public data to investigate whether a self-assessment that the DTC results were easy or very easy to understand was correlated with correctly interpreting the results. In these analyses, participants were scored as correctly interpreting their results if they assessed their risk in the same 
Fig. 4. General public's and genetic counselors' assessment of risk, helpfulness and concern relating to scenario 4 - decreased risk of colon cancer.

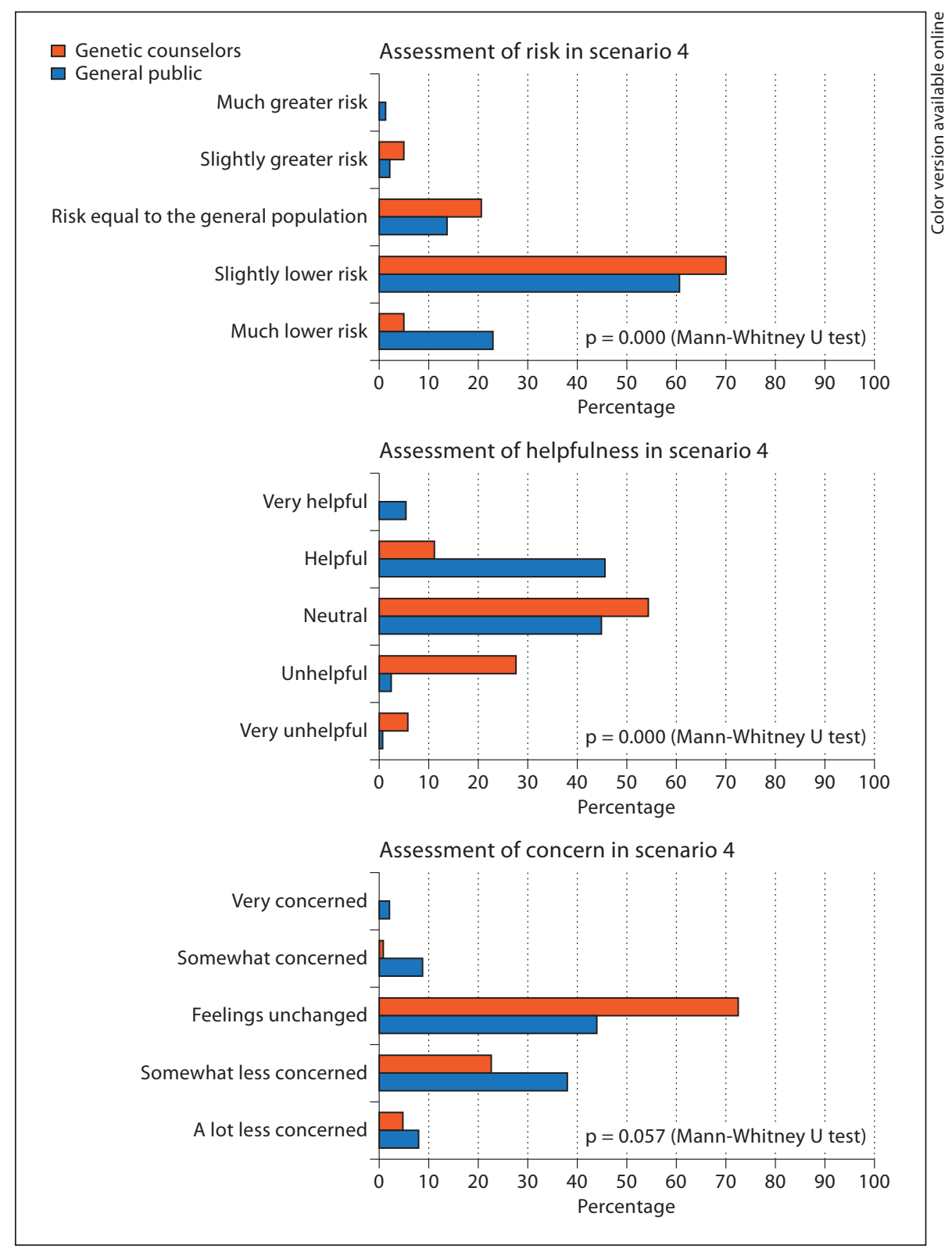

manner as the majority of the comparison group of genetic counselors. In the first scenario, 71 out of 127 individuals answered that the results were easy or very easy to understand, but only 42 of the 71 (59.2\%) correctly interpreted the results. In the second scenario, 74 out of 118 individuals answered that the results were easy or very easy to understand, and only 46 of those individuals $(62.2 \%)$ correctly interpreted the results. In the fourth scenario, 80 out of 103 individuals answered that the results were easy or very easy to understand, and only 51 of those individuals $(63.8 \%)$ correctly interpreted the re- sults. The results for all 3 of these scenarios (1,2 and 4) did not represent a significant difference $(p=1, p=0.292$ and $\mathrm{p}=0.315$ ), meaning that an individual did not have a higher probability of correctly interpreting the results when he/she thought that the results were easy to understand. However, in the third scenario, 80 out of 115 individuals answered that the results were easy or very easy to understand, and 64 of those individuals (80.0\%) correctly interpreted the results. This result represented a significant difference $(\mathrm{p}=0.025)$, meaning that an individual had higher probability of correctly interpreting 
the results when he/she thought that the results were easy to understand in scenario 3.

\section{Seeking More Information}

The majority of the general public respondents in this study indicated that they were most likely to seek more information about DTC testing from their own doctors or the internet. Overall, 92 out of 106 (86.9\%) respondents stated that they would seek more information from their doctor, and 83 out of 106 (68.9\%) respondents stated that they would seek more information from the internet.

\section{Discussion}

The results of this study demonstrated a significant difference between the way that individuals from the general public and genetic counselors interpret results from DTC genetic tests in 3 of 4 scenarios presented. It is important to note that despite the significant difference between the overall general public and genetic counselor interpretations, the majority of respondents in the general public interpreted the results correctly. Compared to genetic counselors, we found that the general public consistently felt that the results from the DTC genetic tests would be more helpful in managing future medical care. Finally, these results demonstrated that individuals from the general public were not able to accurately assess if they might benefit from assistance in understanding their DTC genetic test results.

These findings suggest that some members of the general public will need assistance to understand the meaning of their DTC test results. A recent commentary suggested that primary care providers may be ill-prepared to help consumers understand their DTC results [2]. The authors indicated that although most primary care physicians are accustomed to talking about various disease risk factors with patients, they have limited experience with disease risks based on SNP data used by DTC testing companies. Furthermore, most primary care providers may have inadequate time to explain the meaning and implications of the results to their patients [2]. Given their training in explaining complex genetic testing results, genetic counselors are likely to be increasingly involved in helping consumers understand the implications of genomic test results, including results from DTC genetic tests $[5,19]$. For this reason, genetic counselors were used as a comparison group for assessing the extent to which members of the general public understand DTC test results.

General Public's Understanding and

Perception of DTC Genetic Tests
This study has shown that individuals from the general public may be better able to understand their genetic risk from DTC tests if in addition to providing information about relative risk or absolute risk, a qualitative interpretation of the results is included, such as in scenario 3 , which stated 'slightly lower odds of developing basal cell carcinoma'. As suggested by Lipkus [20], presentation of risk using both numeric risks and phrases to convey the magnitude of the probability could improve the efficacy of risk communication. Since all information relating to the risk of developing a disease based on genetics will be probabilistic, additional research is needed to assess outcomes of communication using various formats for conveying the likelihood of an event occurring.

The most likely explanation for the misunderstanding of DTC genetic test results is that the participants had trouble comprehending and attaching meaning to the numerical risk values utilized in the sample test results, which has been termed numeracy [13]. Although numeracy was not directly measured in this study, studies have consistently shown that numeracy levels among members of the general public are generally low [13-15]. Research has shown that low numeracy skills can lead to the development of inappropriate risk perceptions [14], which may provide a possible explanation for the results of this study. Additionally, since individuals with higher levels of education have been shown to have the highest levels of numeracy [14] and the participants in this study were highly educated, with greater than $81 \%$ holding at least a Bachelor's degree, it is likely that participants in this study were more able to understand DTC genetic test results than the general public as a whole. Thus, the results in this study may in fact underestimate misunderstanding among members of the general public regarding DTC genetic tests.

The results from this study also demonstrated that the general public consistently felt that the DTC genetic test results would be significantly more helpful $(p<0.05)$ in managing future medical care than did genetic counselors. There are several possible explanations for this difference. The general public may feel that the information from the DTC test results implies a much greater impact on the overall risk for disease than otherwise indicated, which could be attributed to misinterpretation of the results [21]. Another possible explanation might be greater awareness of the questions surrounding the clinical validity and utility of DTC results among genetic professionals as compared to the general public. As suggested by O'Daniel et al. [22], genetics professionals are often skeptical about genomic risk information, and they tend 
to recognize that the recommendations for behavioral change based on test results are similar to recommendations for healthy living in general.

This difference in the belief in helpfulness is an important area for future investigation because although disease risks conferred by DTC genetic tests are often comparable to those ascribed to family history and lifestyle, some recent research has indicated that a portion of the general public might be more likely to take action to reduce their overall risk for disease in response to their DTC genetic test results [23]. To date, little research has explored the extent to which the relatively small risks derived from DTC tests might influence a person to take action to reduce their risk compared to behavioral changes made in response to other risk information derived from family history or lifestyle. It is possible that disease risks attributed to DTC genetic test results are interpreted as more individualized compared to risks based on lifestyle factors which address the general population more broadly.

This study found a difference between the general public and genetic counselors in the amount of concern caused by the DTC genetic test results in only one out of four scenarios. Interestingly, the difference in concern occurred with regards to the scenario that implied a decreased risk for heart disease. It is possible that the increased concern is attributable to the fact that the participants from the general population were unaware of their a priori risk for heart disease and that even though their risk for developing heart disease was slightly decreased according to the DTC test result, the overall risk was still much higher than they anticipated before participating in the survey and seeing these sample DTC genetic test results $[14,24]$. And although there was not a significant difference in the amount of concern after the DTC test results between the general public and genetic professionals in the other 3 scenarios, at least $10 \%$ of the general public would be concerned about their DTC results in each scenario. Understanding the reason for this concern is important because causing unnecessary worry has been voiced as a possible adverse consequence of DTC genetic testing [3].

Individuals who feel uncomfortable and/or unable to interpret their DTC results may be motivated to seek additional help in order to understand their results. This study indicated that the two most likely sources people might turn to are their own doctor (85\% of general public participants) and the internet (70\%). The adequacy of these two sources in providing information regarding the interpretation of DTC results has yet to be assessed fully. Because of time limitations and documented inadequate understanding of genetics, primary care providers are unlikely to be ideally suited to answer patients' questions relating to DTC test results [2]. Currently, it is unclear where consumers might look on the internet for more information about the interpretation of their DTC genetic test results. If they consult websites of companies offering DTC genetic testing, most are likely to struggle with the information included given high literacy demand and the poor organization of the materials included on the websites [18]. Further research is needed to explore where consumers might seek such information and optimal methods for presenting the information.

This study demonstrated that a substantial portion of individuals overestimated their ability to correctly interpret DTC genetic test results. If consumers assume that the results are easy to interpret, they may not seek assistance with result interpretation, which could lead to taking action based on incorrect interpretation of their results. This possible misunderstanding of the meaning and/or significance of DTC genetic test results could have several possible negative consequences including false reassurances, unnecessary anxiety and unwarranted medical interventions $[1,2]$. Thus, it is important to offer resources to assist consumers with interpretation of their test results so as to avoid adverse outcomes due to misunderstanding of test results.

Limitations to the current study should be noted. The general public sample used in this study is not representative of the U.S. population as a whole. Participants in this study were relatively young, well educated, largely Caucasian, and a large proportion of the sample had a college degree or is currently working in a field related to biological sciences and/or healthcare. Additionally, all general public participants were members of Facebook, and the majority was familiar to the first author or in the social network through Facebook of people known to him. The extent to which their responses might differ from other Facebook users is unknown. In addition, only a small portion of eligible genetic counselors responded to the survey. Participating genetic counselors could differ from those who did not participate with regard to interest in, concerns about or understanding of DTC genetic testing in significant ways.

\section{Conclusions}

This study demonstrated that the general public is at risk for misunderstanding DTC genetic test results if left to interpret them on their own. Additionally, we have 
shown that members of the general public may overestimate the helpfulness of DTC genetic test results in managing their future medical care. Unfortunately, it appears that many consumers are unable to self-assess if they need help in interpreting their own results. Thus, it is important to assist all adopters of DTC genetic testing in order to ensure that everyone is able to correctly understand the meaning and significance of their results. Without assistance, DTC results may lead to false reassurance, unnecessary anxiety or an inappropriate change in future medical management. More studies are needed to gauge the general public's interest in DTC testing as well as consumers' abilities to understand and interpret their DTC results. Although DTC genetic testing can provide consumers with personalized disease risk information, resources need to be made available to minimize possible adverse consequences of DTC testing. This will be especially important in the coming years as DTC testing becomes more affordable and widely used by members of the general public.

\section{References}

1 Hogarth S, Javitt G, Melzer D: The current landscape for direct-to-consumer genetic testing: legal, ethical, and policy issues. Annu Rev Genomics Hum Genet 2008;9: 161-182.

2 McGuire AL, Burke W: An unwelcome side effect of direct-to-consumer personal genome testing: raiding the medical commons. JAMA 2008;300:2669-2671.

3 Offit K: Genomic profile for disease risk: predictive or premature? JAMA 2008;299: 1353-1355.

4 McGuire AL, Diaz CM, Wang T, Hilsenbeck SG: Social networkers' attitudes toward direct-to-consumer personal genome testing. Am J Bioeth 2009;9:3-10.

5 Wade $\mathrm{CH}$, Wilfond BS: Ethical and clinical practice considerations for genetic counselors related to direct-to-consumer marketing of genetic tests. Am J Med Genet C Semin Med Genet 2006;142C:284-292.

-6 Manolio TA: Genomewide association studies and assessment of the risk of disease. New Engl J Med 2010;363:166-176.

7 Easton DF, Pooley KA, Dunning AM, Pharoah $\mathrm{PD}$, Thompson $\mathrm{D}$, Ballinger DG, Struewing JP, Morrison J, Field H, Luben R, Wareham N, Ahmed S, Healey CS, Bowman $\mathrm{R}$; SEARCH collaborators, Meyer KB, Haiman CA, Kolonel LK, Henderson BE, Le Marchand L, Brennan P, Sangrajrang S, Gaborieau V, Odefrey F, Shen CY, Wu PE, Wang HC, Eccles D, Evans DG, Peto J, Fletcher O, Johnson N, Seal S, Stratton MR, Rahman N, Chenevix-Trench G, Bojesen SE, Nordestgaard BG, Axelsson CK, Garcia-Closas M, Brinton L, Chanock S, Lissowska J, Peplonska B, Nevanlinna H, Fagerholm R, Eerola H, Kang D, Yoo KY, Noh DY, Ahn SH, Hunter DJ, Hankinson SE, Cox DG, Hall P, Wedren S, Liu J, Low YL, Bogdanova N, Schürmann P, Dörk T, Tollenaar RA, Jacobi CE, Devilee P, Klijn JG, Sigurdson AJ, Doody MM, Alexander BH, Zhang J, Cox A, Brock IW, MacPherson G, Reed MW, Couch FJ, Goode EL, Olson JE, Meijers-Heijboer H, van den Ouweland A, Uitterlinden A, Riva- deneira F, Milne RL, Ribas G, GonzalezNeira A, Benitez J, Hopper JL, McCredie M, Southey M, Giles GG, Schroen C, Justenhoven C, Brauch H, Hamann U, Ko YD, Spurdle AB, Beesley J, Chen X; kConFab; AOCS Management Group, Mannermaa A, Kosma VM, Kataja V, Hartikainen J, Day NE, Cox DR, Ponder BA: Genome-wide association study identifies novel breast cancer susceptibility loci. Nature 2007;447:1087-1093.

-8 Hirschhorn JN, Lohmueller K, Byrne E, Hirschhorn K: A comprehensive review of genetic association studies. Genet Med 2002; 4:45-61.

-9 American College of Medical Genetics Board of Directors: ACMG statement on direct-to-consumer genetic testing. Genet Med 2004;6:60.

10 Borry P, Cornel MC, Howard HC: Where are you going, where have you been: a recent history of the direct-to-consumer genetic testing market. J Community Genet 2010;1:101106.

-11 Paynter NP, Chasman DI, Pare G, Buring JE, Cook NR, Miletich JP, Ridker PM: Association between a literature-based genetic risk score and cardiovascular events in women. JAMA 2010;303:631-637.

12 Geransar R, Einsiedel E: Evaluating online direct-to-consumer marketing of genetic tests: informed choices or buyers beware? Genet Test 2008;12:13-24.

13 Nelson W, Reyna VF, Fagerlin A, Lipkus I, Peters E: Clinical implications of numeracy: theory and practice. Ann Behav Med 2008; 35:261-274.

14 Kelly KM, Graves KD, Harper FW, Schmidt JE, Dickson SL, Andrykowski MA: Assessing perceptions of cancer risk: does mode of assessment or numeracy matter? Cancer Detect Prev 2007;31:465-473.

15 Kutner M, Greenberg E, Baer J: A first look at the literacy of America's adults in the 21st century (NCES 2006-470). US Department of Education, National Center for Education Statistics. Washington, D.C., US Government Printing Office, 2005.
16 Yamagishi K: When a $12.86 \%$ mortality is more dangerous than $24.14 \%$ : implications for risk communication. Appl Cogn Psychol 1997;11:495-506.

17 Lipkus IM, Samsa G, Rimer BK: General performance on a numeracy scale among highly educated samples. Med Decis Making 2001; 21:37-44.

18 Lachance CR, Erby LA, Ford BM, Allen VC, Kaphingst KA: Informational content, literacy demands, and usability of websites offering health-related genetic tests directly to consumers. Genet Med 2010;12:304-312.

19 O'Daniel JM: The prospect of genome-guided preventive medicine: a need and opportunity for genetic counselors. J Genet Couns 2010;19:315-327.

20 Lipkus IM: Numeric, verbal and visual formats of conveying health risks: suggested best practices and future recommendations. Med Decis Making 2007;27:696-713.

21 Eng C, Sharp R: Bioethical and clinical dilemmas of direct-to-consumer personal genomic testing: the problem of misattributed equivalence. Sci Transl Med 2010;2:1-5.

22 O'Daniel JM, Haga SB, Willard HF: Considerations for the impact of personal genome information: a study of genomic profiling among genetics and genomics professionals. J Genet Couns 2010;19:387-401.

-23 McBride C, Alford SH, Reid RJ, Larson EB Baxevanis A, Brody L: Characteristics of users of online personalized genomic assessments: implications for physician-patient interactions. Genet Med 2009;11:582587.

24 Han PK, Lehman TC, Massett H, Lee SJ, Klein WM, Freedman, AN: Conceptual problems in laypersons' understanding of individualized cancer risks: a qualitative study. Health Expect 2009;12:4-17. 